\title{
MODEL FOR DETERMINING THE CONSUMPTION OF MACHINERY, TABLEWARE, FUEL, OILS AND LUBRICANTS WITH THE PARTICIPATION OF UNITS FROM THE BULGARIAN ARMY IN HUMANITARIAN OPERATIONS
}

\author{
Nikolay NICHEV \\ nbnichev@nvu.bg \\ “VASIL LEVSKI” NATIONAL MILITARY UNIVERSITY, VELIKO TARNOVO, BULGARIA
}

\begin{abstract}
Regulating documents of the Bulgarian Army considered norms for support classic combat operations and in fact Bulgarian Army has no planning methods to be used for planning of humanitarian operations. Solving this problem can be achieved through the use of planning factors. Planning factors are generally based on experience or data on the use of resources from previous operations. The participation of units of the Bulgarian Army in humanitarian operations have failed to bring to the accumulation of data needed to create a suitable planning factors. The purpose of the study is to develop a model by which to bring out planning factors in determining the the consumption of machinery, tableware, fuel, oils and lubricants with the participation of units from the Bulgarian Army in humanitarian operations.
\end{abstract}

\section{KEYWORDS:}

Planning factors, humanitarian operations, planning of operations.

\section{Introduction}

Regulating documents of the Bulgarian Army considered norms for support classic combat operations and in fact Bulgarian Army has no planning methods to be used for planning of humanitarian operations. Solving this problem can be achieved through the use of planning factors. Planning factors are generally based on experience or data on the use of resources from previous operations. The participation of units of the Bulgarian Army in humanitarian operations has failed to bring to the accumulation of data needed to create a suitable planning factor. The national armed forces are called upon to perform a wide variety of contingency operations, which in practice have proved to be operations other than war. These operations include humanitarian operations, in many cases, the armed forces may be tasked to support these operations 
for an extended period of time and depending on the current situation they to be the main or even sole insurance authority (Gordon, 2001; Nichev, 2009).

\section{Planning factors}

According to NATO Glossary of Terms and Definitions (2015) the planning factor is a multiplier used in planning to estimate the amount and type of effort involved in a contemplated operation. Planning factors are often expressed as rates, ratios, or lengths of time.

Allied Joint Logistic Doctrine (2003) determined Logistic Planning Factors as a listing of relationships between two or more variables, e.g., $\mathrm{kgs} / \mathrm{man} / \mathrm{day}$, which can be used to plan resource needs in detail. If they are not readily available, they should be developed and applied when planning a specific mission.

For the purpose of this article the following definition is used: planning factor is a numerical multiplier used in planning that defines the qualitative relationship between the people in need of help and the quantity of the needed resources (Sullivan, 1995).

The requirements to the logistics planning factors are: to help determine the amount and composition of the resources, hence - the necessary funds for their procurement; to assist in determination of material and transport requirements in support of humanitarian operation; to be flexible, influenced by the specific scenario; to be realistic; to be simple to use because the planning personnel switch frequently in order to minimize to the time for entering the work; to allows assessment of large number of situation; to allow the logistics authorities to develop different before a complex crisis occurs and to allow quantification of humanitarian activities carried out by the AF, ie to be described by numerical value.

The national armed forces are called upon to perform a wide variety of contingency operations, which in practice have proved to be operations other than war. These operations include humanitarian operations, in many cases, the armed forces may be tasked to support these operations for an extended period of time and depending on the current situation they to be the main or even sole insurance authority (Nichev, 2009).

To fulfill their role, the planning factors should be tied to the needed material resources for the humanitarian operation. The use of material resources classes provides a standardized to classification of the materials needed for these operations.

To achieve operativeness between the supply units in Bulgarian Army and implementation of delivery of material resources, for the country has been accepted and approved 5- class system for identification of supply classes in BA, consistent with the supply system in NATO (Bulgarian Army logistics Doctrine, 2013).

Classes of material resources used in Bulgarian Army are not the most suitable for humanitarian operations. In humanitarian operations the most important things are food, shelter, medical care and clothing. Taking this in mind, Class II and Class III will be the center of the survey. Table no. 1 summarizes the classes and subclasses of material resources, included in this model.

Table no. 1

Classes, subclasses and types of material resources included in the model

\begin{tabular}{|l|l|l|}
\hline $\begin{array}{c}\tilde{\delta} \\
\tilde{\Xi}\end{array}$ & Subclass & \multicolumn{1}{|c|}{$\begin{array}{c}\text { Type of material } \\
\text { resources }\end{array}$} \\
\hline \multirow{4}{*}{ II } & $\begin{array}{l}\text { Machi- } \\
\text { nery }\end{array}$ & $\begin{array}{l}\text { Vehicles, means for } \\
\text { food preparing, } \\
\text { generators for electricity, } \\
\text { means for extracting } \\
\text { and purifying water, etc. }\end{array}$ \\
\cline { 2 - 3 } & $\begin{array}{l}\text { Table- } \\
\text { ware }\end{array}$ & $\begin{array}{l}\text { Disposable tableware, } \\
\text { means for carrying food, } \\
\text { utensils for cooking }\end{array}$ \\
\hline \multirow{2}{*}{ III } & $\begin{array}{l}\text { Fuel, oils } \\
\text { and lubri- } \\
\text { cants }\end{array}$ & $\begin{array}{l}\text { Fuel, oils and lubricants } \\
\text { cants }\end{array}$ \\
\hline
\end{tabular}


A number of researchers revealed links between humanitarian action and military conflicts (Slim, 2001; Dimitrova \& Nichev, 2011; Zitelli, 2016). In the studied literature there is no working data for the wide range of humanitarian operations. In the publications devoted to summarizing the experience of humanitarian operations, generally shows data for absolute number of people supported or the volume of assistance in quality or quantity value. This requires alternative methods to be used for determination of the planning factors.

\section{Method for Development of} Planning Factor Planning Factors for Machinery

Material resources of Class II, subclass "Machinery" include all technical facilities needed to maintain the affected population. Main facilities are: equipment used for transportation of the population and material resources; machinery for preparation of food; machinery for backing bread; equipment for acquisition, filtration, preservation and transportation of water and machinery for production of electricity. The draw of planning factors for Class II Machinery is based on the norms of the AF, taking into account the fact that the technique is intended to assist the affected civilian population.

To determine the required number of vehicles for delivery of solid and liquid cargo and transportation of the affected population is used the following formula:

$$
\mathrm{Q}_{\mathrm{ts}_{\mathrm{j}}}=\frac{\mathrm{Q}_{\mathrm{r}_{\mathrm{j}}} * \mathrm{R}}{\mathrm{K}_{\mathrm{t}_{\mathrm{j}}} * \mathrm{~V}_{\mathrm{sr}_{\mathrm{j}}} * \mathrm{~T}_{\mathrm{j}} * \mathrm{k}}
$$

where:

$$
Q_{t_{j}}-\text { needed vehicles of type } j
$$

[number];

$$
\mathrm{Q}_{\mathrm{r}_{\mathrm{j}}} \text { - amount of resources, subjected }
$$

to transportation with vehicles of type $\mathrm{j}[\mathrm{kg}]$; evacuation
$\mathrm{K}_{\mathrm{t}_{\mathrm{j}}}$ - cargo capacity of vehicles of type $\mathrm{j} ;[\mathrm{kg}]$

$\mathrm{T}_{\mathrm{j}}$ - duration of workday of vehicles of type $\mathrm{j}$ [hrs];

$\mathrm{k}$ - coefficient, rendering the loss of working time - accepted 0,7-0,9

To determine the number of machinery for backing bread and for acquisition and filtration of water, the following formula is used:

$$
\mathrm{Q}_{\mathrm{t}_{\mathrm{n}}}=\frac{\mathrm{Q}_{\mathrm{r}_{\mathrm{n}}} *\left(1-\mathrm{S}_{\mathrm{n}}\right)}{\mathrm{K}_{\mathrm{n}} * \mathrm{~T}_{\mathrm{n}} * \mathrm{k}}
$$

where:

$\mathrm{Q}_{\mathrm{t}_{\mathrm{n}}}$ - needed machinery of type " $\mathrm{n}$ "; [number]

$\mathrm{Q}_{\mathrm{r}_{\mathrm{n}}}$ - needed resources, obtained by machinery of type " $\mathrm{n}$ " [kg], [1tr]

$\mathrm{S}_{\mathrm{n}}$ - coefficient, rendering the ability of the infrastructure to ensure resources, obtained by machinery of type " $n$ ", expressed as a proportion of ensured to needed amount of resources, taking values from $0 \div 1$.

$\mathrm{K}_{\mathrm{n}}$ - productive capacity of machinery of type " $\mathrm{n}$ " per hour; [kg/h], [ltr/ h]

$\mathrm{T}_{\mathrm{n}}$ - number of hours that machinery works per day $[\mathrm{h}]$

$\mathrm{k}$ - coefficient, rendering the loss of working time

To determine the necessary number of machinery for food preparation and units for production of electricity to satisfy the needs of the affected population we use the following formula:

$$
\mathrm{Q}_{\mathrm{t}_{\mathrm{k}}}=\frac{\mathrm{Q}_{\mathrm{r}_{\mathrm{k}}} *\left(1-\mathrm{S}_{\mathrm{k}}\right)}{\mathrm{K}_{\mathrm{k}}}
$$

where:

$$
\mathrm{Q}_{\mathrm{t}_{\mathrm{k}}} \text { - needed machinery of type " } \mathrm{k} \text { " }
$$
[number];

$\mathrm{Q}_{\mathrm{r}_{\mathrm{k}}}$ - maximum number of staff, supplied with machinery of type " $k$ "; [number] 
$\mathrm{S}_{\mathrm{k}}-$ coefficient, rendering the ability of the infrastructure to ensure resources, obtained by machinery of type " $k$ ", expressed as a proportion of ensured to needed amount of resources, taking values from $0 \div 1$;

$\mathrm{K}_{\mathrm{k}}$ - number of staff, supplied with machinery of type "k" per day; [number]

After the general number of needed machinery is defined, the general weight of the equipment is calculated by the formula:

$$
T_{t}=\sum Q_{t_{i}} * T_{t_{i}}
$$

where:

$\mathrm{T}_{t}-$ general weight of the needed machinery

$\mathrm{Q}_{\mathrm{ti}}$ - general number of equipment " $\mathrm{i}$ “"

$\mathrm{T}_{\mathrm{ti}}$ - weight of "I" - equipment

The planning factor for machinery is calculated as $T_{t}$ is divided by the number of the assisted population.

\section{Method for Development Planning Factors for Tableware}

The necessary material resources of Class II - tableware are wholly dependable on the established organization for cooking and feeding of the affected population. The possible ways of organizing the feeding of the seeking protection populations are: centralized preparation and distribution of food and feeding of the population; centralized preparation and distribution of food and decentralized feeding of the population; decentralized preparation of the food and feeding the population using individual food packages (UNHCR Handbook for Emergencies, 2007). Depending on the specific tactical and humanitarian situation, it is possible the feeding of the population, seeking protection, to be carried out in mixed method (Figure no. 1).

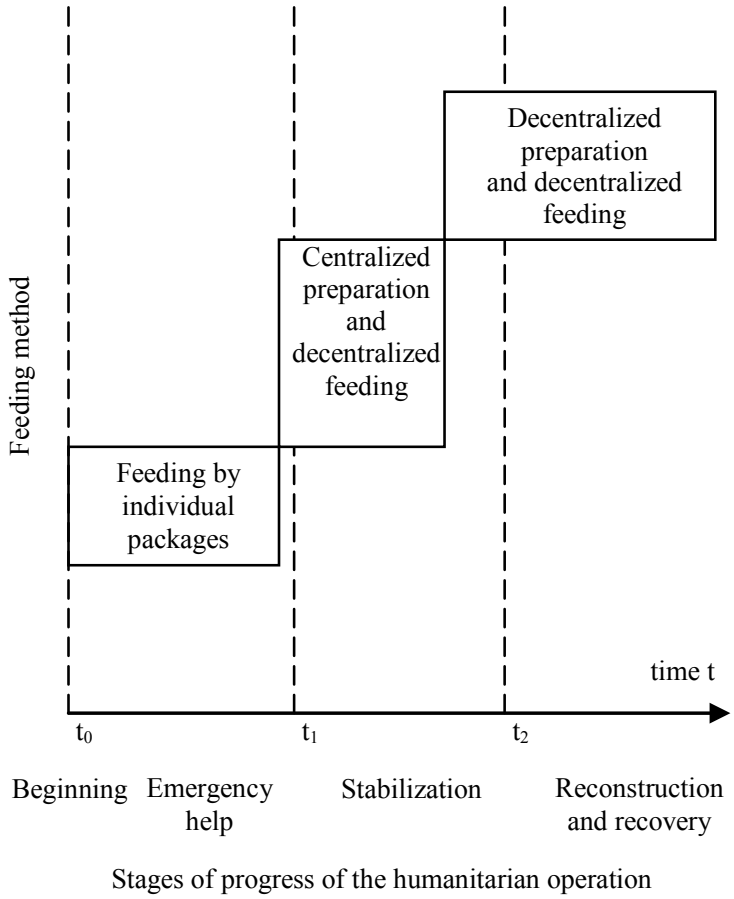

Figure no. 1 Exemplary diagram for feeding in mixed method

According to the approved by the commander of the humanitarian operation method of feeding and the planning factors, the logistics planning authorities determine the need and announce the necessary amounts of material resources. Table 2 summarizes the logistical planning factors for material resources of Class II tableware.

Table no. 2

Planning factors for tableware, included in the model

\begin{tabular}{|c|l|c|}
\hline № & \multicolumn{1}{|c|}{ Material resources } & $\begin{array}{c}\text { Planning } \\
\text { factor [kg.] }\end{array}$ \\
\hline 1. & $\begin{array}{l}\text { Assets for carrying } \\
\text { and distribution of } \\
\text { food }\end{array}$ & 0,406 \\
\hline 2. & $\begin{array}{l}\text { Accessories for } \\
\text { centralized preparation } \\
\text { of food }\end{array}$ & 0,385 \\
\hline 3. & Kitchen kit & 1,326 \\
\hline 4. & Disposal tableware & 0,109 \\
\hline
\end{tabular}


5. Method for Development of the Planning Factors for Fuel, Oils and Lubricants

In its work the logistics authorities for providing fuel, oils and lubricants for Bulgarian Army, five main methods for calculation of the necessary quantities of fuel are used: statistical, by intensity per vehicle used, by intensity per vehicle used of particular make and model, by intensity of the whole quantity vehicles used and by consumption of fuel.

From the analysis of the planning methods for the needs of material resources Class III - fuel, oils and lubricants, it is clear that their in-time planning requires applying integrated methodology for calculating the levels of the daily needs for fuel, oils and lubricants. This is complemented by the fact that daily fuel consumption of fuel, oils and lubricants varies accordingly to the dynamics of the humanitarian operation (Dimitrov et al., 2008).

Basis for calculation of the needs for fuel are average expenditure norms of fuel for each consumer per day. To calculate the need for fuel, the following formula is used:

$$
P_{G_{i}}=H^{*} B * k_{1} * k_{2} * k_{3} * k_{4}
$$

where: [liters]

$P_{G i}-$ need for fuel for i-consumer

$\mathrm{H}$ - average quantity of fuel, consumed per day by one consumer [liter/day]

$\mathrm{B}$ - number of consumers [number]

$k_{1}$ - coefficient, rendering the daily run or the work duration of the aggregates for the specific conditions of the operation. Its calculation is made by:

$$
k_{1}=\frac{P_{1}}{P_{2}}
$$

where:

$P_{1}$ - presumed average daily run of the vehicles $[\mathrm{km}]$, or the presumed average daily work duration of the aggregates for particular operation
$P_{2}$ - average daily run of the vehicles $[\mathrm{km}]$, or average daily duration of work in hours of the stationery and mobile engines, machinery and equipment [hours], on the basis of which are calculated the averaged expenditure norms for fuel, oils and lubricants

$k_{2}$ - coefficient, rendering the affection of the climate factors, varying in the range 0.9-1.3

$k_{3}-$ coefficient, rendering the affection of the terrain in the zone of operation, varying in the range 1.0-1.5

$k_{4}-$ coefficient, rendering the affection of the type of the operation, varying in the range 1.0-2.4

The need for lubricants is calculated as a percent of the consumed fuel and is determined by the following formula:

$$
P_{S M_{i}}=P_{o p} * a+P_{t o}
$$

where:

$P_{S M_{i}}$ - need for lubricants for $\mathrm{i}$ consumer [liters] ;

$P_{o p}$ - common need for fuel for the vehicles [liters]

$a$ - percent of the prescribed oils and lubricants depending on the common fuel expenditure

$P_{t o}-$ need for oils and lubricants for technical maintenance, they are determined according to the approved expenditure norms [liters].

The planning factors for Class III are drawn by dividing amount of needed fuel, oils and lubricants for particular consumer to the number of people served by that consumer, as shown in the next formula:

$$
P F_{G S M_{i}}=\frac{P_{G S M_{i}}}{L S}
$$

where:

$P F_{G S M}$ - planning factor for fuel, oils and lubricants for consumer i [liters];

$\mathrm{P}_{\mathrm{GSMi}}$ - need for fuel or lubricants for consumer i [liters]; 
$L S$ - number of people seeking help [number].

The determination of the need for material resources for Class III - fuel, oils and lubricants in the humanitarian operation characterizes by the fact that it could not be given a precise quantitative expression of the same. This is dictated by the specific features of fuel, oils and lubricants supply in humanitarian operation and the variety of factors, affecting the fuel, oils and lubricants expenditure.

\section{Conclusion}

1. Planning the need for material resources Class II - machinery tableware and Class III - fuel, oils and lubricants in conducting operative and tactical planning for conducting humanitarian operations shows that the use of planning factors is an effective and rapid for its accomplishment.
The timely planning of the need for material resources is a crucial factor for a positive course and a positive result of humanitarian operations.

2. It is necessary to develop and validate the methodology and specialized instructions and manuals for planning the needs to satisfy the needs of the people, seeking protection and help, when planning and conducting humanitarian operation by Bulgarian Army units.

3. Knowing, learning and practical mastering the requirements of the international humanitarian community and the abilities of Bulgarian Army to implement them and the developed on the same basis planning factors will contribute the capabilities of the Bulgarian armed forces for effective conduction of humanitarian operations.

\section{REFERENCES}

Bulgarian Army Headquarters. (2013). Bulgarian Army Logistics Doctrine, Sofia, Bulgaria: Military Publishing House.

Dimitrov, M., Dimitrov L. \& Stefanov, I. (2008). Fundamentals of multinational logistics, Sofia, Bulgaria: “Georgi Stoykov Rakovski” National Defense College.

Dimitrova, S. \& Nichev, N. (2011). Analysis of modern humanitarian operations concepts and participation of military units, Land Forces Academy Review, Vol. 16, No. 4, 348-355.

Gordon S. (2001). Understanding the priorities for civil-military co-operation, The Journal of Humanitarian Assistance, available at: http://www.jha.ac/articles/a068.htm.

Bulgarian Army Headquarters. (2006). Methodology for planning and setting up military stocks of material resources for the declared units of the bulgarian army to participate in the full range of NATO operations, Sofia, Bulgaria: Military Publishing House

Nichev, N. (2009). Historical analysis of the involvement of joint armed forces in humanitarian operations, $15^{\text {th }}$ International Conference on Knowledge-Based Organization, Vol. 1, "Nicolae Bălcescu” Land Forces Academy, Sibiu, Romania, 104-108.

North Atlantic Treaty Organization. (2003). AJP-4 Allied Joint Logistic Doctrine, available at: www.nato.int/docu/stanag/ajp4/ajp-4.pdf.

North Atlantic Treaty Organization. (2015). NATO Glossary of terms and definitions, AAP-06, STANAG 3680.

Slim H. (2001). Military intervention to protect human rights: The humanitarian agency perspective, ICHRP - International council on human rights policy, available at: http://www.ichrp.org/files/papers/50/115_Military_Intervention_to_Protect._Human_Rights Slim_Hugo_2001_background paper.pdf. 
Sullivan, D. (1995). Logistic planning and logistics planning factors for humanitarian operations, available at: http://www.dtic.mil/cgi-bin/GetTRDoc?AD=ADA303995\& Location $=\mathrm{U} 2 \&$ doc $=$ GetTRDoc.pdf.

United Nations High Commissioner for Refugees (2007), UNHCR Handbook for emergencies, $3^{\text {rd }}$ edition, available at: http://www.unhcr.org/publ/PUBL/471db4c92.html.

Zitelli, G. (2016). Blood aid how humanitarian aid empowers warlords and prolongs conflict. International Affairs Review, available at: http://www.iar-gwu.org/content/blood-aidhow-humanitarian-aid-empowers-warlords-and-prolongs-conflict. 